\title{
Open Borders and the Right to Immigration
}

\author{
Peter Higgins
}

Published online: 19 March 2008

(c) Springer Science + Business Media B.V. 2008

\begin{abstract}
I do not argue for or against substantive immigration policies in this paper. Rather, my thesis concerns what kinds of reasons are morally salient in the construction of just immigration policies. I argue that philosophical proposals for regulating immigration should be evaluated according to the following methodological principle: The unit of analysis in terms of which principles for regulating immigration must be evaluated is the socially situated individual. I defend this principle indirectly by applying it to cosmopolitan principles for regulating immigration in order to demonstrate the moral inadequacy of theories of immigration that adopt an inappropriate unit of analysis. Failure to evaluate the moral adequacy of their own substantive proposals in terms of their effects on socially situated individuals leads some cosmopolitans to endorse substantive recommendations for regulating immigration (namely, open borders) that, I argue, disproportionately burden members of institutionally disadvantaged groups.
\end{abstract}

Keywords Immigration - Cosmopolitanism - Open borders - Global justice . Disadvantaged social groups · Non-ideal theory - Global poverty - Brain drain . Remittances

Cosmopolitans have defended, for a variety of reasons, the elimination of most restrictions on immigration. In this paper, 1 distinguish between two general cosmopolitan strategies for justifying the claim that states ought to open their borders, in order to argue against one of these approaches.'

\footnotetext{
1 While different cosmopolitan theorists are more or less precise about which countries they mean their defense of open borders to apply to, 1 will assume that these theorists primarily intend to apply their conclusions to the admissions policies of affluent liberal states. All cosmopolitan defenses of open borders apply at least to affluent liberal states. However, some cosmopolitan defenses of open borders presumably apply only to affluent countries (given the premises of these arguments). Others seem to apply only to liberal states, as defenders of those arguments often admit (since the premises of those arguments are grounded in essentially liberal assumptions).
}

P. Higgins (诃)

Philosophy Department, UCB 232, Boulder, CO 80309, USA

e-mail: Peter.Higgins $(\omega)$ Colorado.edu 
I do not argue for or against substantive immigration policies in this paper, restrictive or porous. Rather, my thesis concerns what kinds of reasons are morally salient in the construction and justification of just immigration policies. In this paper, I argue that philosophical proposals for regulating immigration should be evaluated according to the following methodological principle:

The unit of analysis in terms of which principles for regulating immigration must be evaluated is the socially-situated individual. ${ }^{2}$

That is, in order to determine whether and to what extent a state's immigration policies are just, one must observe its effects and implications for socially situated individuals. A person is socially situated by her relation to social institutions; for example, a person may be socially situated by her gender, race, class, age, ability, sexuality, religion, nationality, caste, profession, political affiliation, and other salient aspects of her identity as determined by dominant cultural values and practices.

1 do not positively defend this methodological principle here. Nevertheless, I defend this principle indirectly by applying it to cosmopolitan principles for regulating immigration in order to demonstrate the moral inadequacy of theories of immigration that adopt an inappropriate unit of analysis. I understand this principle as a necessary, but not sufficient, condition that principles for regulating immigration must satisfy in order to be just. Ultimately, I will argue that certain cosmopolitan approaches to immigration implicitly adopt a faulty unit of analysis by which to evaluate their defense of open borders. Failure to evaluate the moral adequacy of their own substantive proposals in terms of their effects on socially situated individuals leads some cosmopolitans to endorse substantive recommendations for regulating immigration (namely, open borders) that, I argue, disproportionately burden members of institutionally disadvantaged groups.

To clarify, by "immigration" I mean to include both the admission of permanent resident aliens as well as the admission of temporary workers, but to exclude the admission of other "non-immigrants." While categories and classes of admission vary from one country to the next, in US law, for example, permanent resident aliens are distinguished from non-immigrants by the fact that non-immigrants only temporarily enter the USA for a specific purpose (while permanent resident aliens, as their classification suggests, enter the country to reside permanently). Temporary workers are considered non-immigrants in US law; however, in this work, I wish to evaluate the principles for regulating the admission of temporary workers along with the principles for regulating the admission of permanent resident aliens. Temporary workers are distinct from other classes of non-immigrants because though they may not intend to reside permanently in the country to which they migrate, their temporary residence in the country to which they migrate is generally fairly extended, in contrast to other classes of non-immigrants, whose length of stay in a foreign country is often fairly abbreviated (such as, for example, visitors for business

\footnotetext{
${ }^{2}$ This constraint can be applied to philosophical principles for regulating immigration as well as substantive immigration policies, since presumably such policies are grounded in particular principles, at least implicitly.
}

or pleasure, or "aliens in transit"). raises moral questions that I belier permanent residents, and more signi

\section{Cosmopolitan Defenses of Open}

While cosmopolitans employ diffe liberal states ought to eliminate re: cosmopolitan, begin with three $n$ Pogge. First, cosmopolitans hold individual human beings, or persor social groups, or states, for exam status of ultimate unit of moral con person, equally. Finally, individual moral concerm for everyone, aci assumptions individualism, univer:

In this paper, I wish to focus moral requirement that affluent lib refer to as "consequentialist cosmor just mentioned with empirical obs inequality in order to argue that aft immigration as one way of (par specific nature) to the global poo "consequentialist cosmopolitanism' view do not characterize their arg theorists who defend open borders consequentialist or cosmopolitan.

Will Kymlicka defends the ado consequentialist cosmopolitan reas

There is one respect in which th I think, be defended - namely, r use and benefits of its citizen: equals. It follows that each pers

\footnotetext{
${ }^{3}$ See the US Citizenship and Immigratic categories.

${ }^{4}$ Thomas Pogge, World Poverty and Hum ${ }^{5}$ Consequentialist cosmopolitanism contre believe is best defended by Phillip Cole ir and Immigration (Edinburgh: Edinburgh $\mathrm{L}$ Cole, combines the fundamental principles similar to the fundamental assumptions of which liberal states in principle treat the consistently, by their own standards, adof Benhabib's The Rights of Others: Alien Press, 2004) also represents a defense of 1 this paper.
} 
or pleasure, or "aliens in transit"). ${ }^{3}$ In addition, the admission of temporary workers

per,

ally

per,

ited raises moral questions that $I$ believe are similar in magnitude to the admission of permanent residents, and more significant than the admission of other non-immigrants.

\section{Cosmopolitan Defenses of Open Borders}

While cosmopolitans employ different strategies to justify the claim that affluent liberal states ought to eliminate restrictions on immigration, all, insofar as they are cosmopolitan, begin with three moral assumptions, as characterized by Thomas Pogge. First, cosmopolitans hold that the ultimate units of moral concern are individual human beings, or persons, as opposed to certain groups, such as families, social groups, or states, for example. Second, all cosmopolitans believe that the status of ultimate unit of moral concern attaches to every individual human being, or person, equally. Finally, individual human beings, or persons, are ultimate units of moral concern for everyone, according to cosmopolitans. Pogge names these assumptions individualism, universality, and generality, respectively. ${ }^{4}$

In this paper, I wish to focus on one particular cosmopolitan rationale for the moral requirement that affluent liberal states open their borders. This view, which I refer to as "consequentialist cosmopolitanism," combines the three moral assumptions just mentioned with empirical observations regarding global poverty and economic inequality in order to argue that affluent liberal states should eliminate restrictions on immigration as one way of (partially) discharging their obligation (whatever its specific nature) to the global poor. ${ }^{5}$ I believe the characterization of this view as "consequentialist cosmopolitanism" is descriptively useful, even if defenders of this view do not characterize their arguments in this way; I do not mean to imply that theorists who defend open borders along these lines can be characterized generally as consequentialist or cosmopolitan.

Will Kymlicka defends the adoption of open borders by affluent liberal states for consequentialist cosmopolitan reasons in the following way.

There is one respect in which the current practice of liberal democracies cannot, I think, be defended - namely, reserving a country's resources for the exclusive use and benefits of its citizens. ...Liberal egalitarians view people as moral equals. It follows that each person's well-being matters equally, from the point

\footnotetext{
${ }^{3}$ See the US Citizenship and Immigration Services website (www.uscis.gov) for delineation of these categories.

${ }^{4}$ Thomas Pogge, World Poverty and Human Rights, Maldon, MA: Polity Press, 2002, p. 169

"Consequentialist cosmopolitanism contrasts with what I call "liberal cosmopolitanism," a view that I believe is best defended by Phillip Cole in his book Philosophies of Exclusion: Liberal Political Theory and Immigration (Edinburgh: Edinburgh University Press, 2000). Very roughly, this view, as defended by Cole, combines the fundamental principles of liberalism (as described by Cole; these principles are quite similar to the fundamental assumptions of cosmopolitans, as described by Pogge above) with the way in which liberal states in principle treat their own citizens, in order to argue that liberal states cannot consistently, by their own standards, adopt exclusive or restrictive immigration policies. I believe Seyla Benhabib's The Rights of Others: Aliens, Residents, and Citizens (Cambridge: Cambridge University Press, 2004) also represents a defense of liberal comspolitanism. I do not take a position on this view in this paper.
} 
of view of liberal theory. Liberal egalitarians cannot accept, therefore, any system of boundaries which condemns some people to abject poverty while allowing others a life of privilege. Yet this is precisely what occurs today, given the grossly unequal international distribution of resources between states, combined with limitations on mobility. ${ }^{6}$

While Kymlicka does not advocate open borders as a first resort for addressing global economic inequalities, arguing, instead, in favor of a global redistributive tax of some kind, he nonetheless contends that if affluent states refuse to redistribute their wealth in a way consistent with the moral equality of individuals, they must open their borders. Kymlicka says, "If rich countries are unwilling to share their wealth in this way, then I think they forfeit the right to restrict admission into their borders. It is not permissible, in the liberal egalitarian view, to restrict admission if this involves hoarding an unfair share of resources."

Similarly, Joseph Carens defends the view that affluent liberal states ought to eliminate restrictions on immigration on consequentialist cosmopolitan grounds. He argues that

Borders should generally be open and...people should normally be free to leave their country of origin and settle in another, subject only to the sorts of constraints that bind current citizens in their new country. The argument is strongest, I believe, when applied to the migration of people from third world countries to those of the first world. Citizenship in Western liberal democracies is the modern equivalent of feudal privilege - an inherited status that greatly enhances one's life chances.

While neither Carens nor Kymlicka characterize their defenses of open borders as consequentialist or cosmopolitan, I believe it is descriptively useful to think of their views on immigration in this way. Both ground their views, at least implicitly, in the cosmopolitan assumptions of individualism, universality, and generality. Moreover, both Carens and Kymlicka defend the adoption of open borders instrumentally, as a means for affluent liberal states to alleviate global poverty and economic inequality.

I will argue in the following portion of this paper that such consequentialist cosmopolitan defenses of open borders violate the methodological principle I set forth at the beginning of this paper by implicitly adopting a morally inappropriate unit of analysis by which to evaluate the moral adequacy of their own proposals. The unit of analysis implicitly adopted by both Carens and Kymlicka, and cosmopolitans generally, is the individual human being. Pogge's characterization of cosmopolitanism makes this clear. In other words, consequentialist cosmopolitans evaluate the justice of proposals for the regulation of immigration in terms of the effects such proposals have

\footnotetext{
"Will Kymlicka, "Territorial Boundaries: A Liberal Egalitarian Perspective," Boundaries and Justice: Diverse Ethical Perspectives, edited by David Miller and Sohail H. Hashmi (Princeton University Press), 2001 , p. 270

7 Will Kymlicka, "Territorial Boundaries: A Liberal Egalitarian Perspective," Boundaries and Justice: Diverse Ethical Perspectives, edited by David Miller and Sohail H. Hashmi (Princeton University Press), 2001, p. 27 !

"Joseph Carens, "Aliens and Citizens: The Case for Open Borders," The Immigration Reader: America in a Multidisciplinary Perspective, ed. David Jacobson, Malden, MA: Blackwell. 1998, pp. 365-6
}

for individual human beings. In w cosmopolitan defenses of open methodological constraint. Briefly, inappropriate unit of analysis leac immigration policies (namely, open of institutionally disadvantaged gror

\section{What's Wrong with Cosmopolita}

The methodological principle I def theorists writing on immigration of social ontologies, Charles Mills ar:

...typically assume the abstract a classical liberalism. Thus it $w$ domination, exploitation, coercic will profoundly shape the ontolc superior and inferior positions it

The methodological principle I . regulation of immigration empl recognizes that individuals are co to institutions of domination. Th policies be evaluated in terms $\mathrm{C}$ ensures that the interests of those regarding the regulation of immis divergent effects of the immigrati situated individuals are acknowlec

Cosmopolitan defenses of open rely on an idealized social ontolor constituted by individuals who are the social institutions of gender cosmopolitan defenses of open defend, according to which the 1 regulating immigration must be $c$ result, such proposals, I argue, hc disadvantaged groups. There are 1

First, while the consequentialist and justified by a concern for the migrate transnationally is a luxu economically speaking, possess. A most by the global economic orde are suffering from easily and chea

\footnotetext{
${ }^{9}$ Charles Mills, "'Ideal Theory" as Ideolo
} 
for individual human beings. In what follows, I will explain why consequentialist cosmopolitan defenses of open borders are unsatisfactory in regard to this methodological constraint. Briefly, I will argue that the adoption of a morally inappropriate unit of analysis leads cosmopolitan theorists to defend substantive immigration policies (namely, open borders) that disproportionately burden members of institutionally disadvantaged groups.

ssing ve $\operatorname{tax}$ ribute must their , their ion if

ght to 1s. $\mathrm{He}$

ave

of

$\mathrm{t}$ is

orld

zies

atly

lers as $f$ their in the eover,

$y$, as a uality. tialist : I set spriate s. The olitans tanism tice of $s$ have

\section{What's Wrong with Cosmopolitan Theories of Immigration?}

The methodological principle I defend is critical of the way in which cosmopolitan theorists writing on immigration often rely on an idealized social ontology. Idealized social ontologies, Charles Mills argues

..typically assume the abstract and undifferentiated equal atomic individuals of classical liberalism. Thus it will abstract away from relations of structural domination, exploitation, coercion, and oppression, which in reality, of course, will profoundly shape the ontology of those same individuals, locating them in superior and inferior positions in social hierarchies of various kinds.'

The methodological principle I defend requires that policies and proposals for the regulation of immigration employ a non-idealized social ontology-one that recognizes that individuals are constituted by, among other things, their relations to institutions of domination. This constraint (which requires that immigration policies be evaluated in terms of their effects on socially situated individuals) ensures that the interests of those whose moral interests are at stake in decisions regarding the regulation of immigration are appropriately considered and that the divergent effects of the immigration policies of various states on uniquely socially situated individuals are acknowledged.

Cosmopolitan defenses of open borders are plausible only to the extent that they rely on an idealized social ontology. An idealized social ontology assumes a world constituted by individuals who are relatively privileged with respect, for example, to the social institutions of gender, race, and class. In this way, consequentialist cosmopolitan defenses of open borders violate the methodological principle I defend, according to which the unit of analysis in terms of which proposals for regulating immigration must be evaluated is the socially situated individual. As a result, such proposals, I argue, harm rather than benefit members of institutionally disadvantaged groups. There are three ways in which this is so.

First, while the consequentialist cosmopolitan defense of open borders is motivated and justified by a concern for the economically least well-off, the material ability to migrate transnationally is a luxury that only those who are relatively privileged, economically speaking, possess. And often, it is not those individuals who are harmed most by the global economic order (those who are severely malnourished, those who are suffering from easily and cheaply preventable or treatable diseases, or those who

\footnotetext{
"Charles Mills, "“Ideal Theory' as Ideology," Hypatia, v. 20, n. 3, (Summer 2005), p. 168
} 
do not have access to safe drinking water, etc.) who could take advantage of open borders policies were they to be implemented by the world's affluent liberal states. Rather, it is the middle classes and the most well-off in countries that are otherwise harmed by the global economic order who would benefit most from such policies. ${ }^{10}$ And so, at best, open border policies would fail to help the economically least well-off-those for whom the liberals' concern motivated them to propose these policies. ${ }^{\text {I }}$

Second, there are reasons to think that open borders are harmful to those who they are supposed to benefit, particularly when the gendered and racialized effects of transnational mobility are considered. Feminist geographers Geraldine Pratt and Brenda Yeoh argue that the kind of transnational mobility that would be fostered by porous national boundaries in liberal states does not necessarily help the global poor. Since other structures of inequality, such as gender and race, are left intact, transnational mobility merely tends to change the ways in which the global poor are harmed. The ability to migrate transnationally, while it may benefit some women in certain ways, generally tends to produce at least as many harms for many racially marginalized women who migrate. Pratt and Yeoh explain:

Women transmigrants, during the sojourn as labour migrants, often find themselves accorded few citizen's and civil rights in destination countries and trapped within patriarchal notions of 'women's work' and 'women's place.' The rules of marginality and 'otherness' which operate to keep transmigrant contract workers in their place are often refracted through the gendered lenses of the host nation; as a result, women transmigrants, when put into a comparative frame with their male counterparts, find their bodies subject to a more oppressive disciplinary framework, their skills further devalorised, and their spaces even more circumscribed. ${ }^{12}$

As Pratt and Yeoh demonstrate, transnational migration is not unqualifiedly liberating even for those who have the means, and this is because, despite the ability to cross national borders, other institutional forms of inequality, such as gender and race, remain in place. It is also plausible to think, following the arguments of Pratt and Yeoh, that the less well-off one is (not only economically, but also with respect to the social institutions

\footnotetext{
"Thomas Pogge appears to make a similar argument in his article "Migration and Poverty" [Citizenship and Exclusion, ed. Veit M. Bader (Houndmilts: Macmillan), 1997, pp. 12 27ן. However, there are two reasons Pogge's arguments in that paper are impertinent here. First, Pogge's thesis in that article is not that affluent liberal states should eliminate immigration restrictions, or that they should not. Rather, it is that cosmopolitans should not advocate the elimination of immigration restrictions because strategically it is more useful, given cosmopolitans' concerns, to advocate reform of the global economic order. Second, to the extent that Pogge does make substantive arguments for and against the adoption of certain immigration policies by affluent liberal states, his arguments only concern the liberalization of restrictions on immigration (as opposed to the elimination of immigration restrictions).

"This argument is not intended to be decisive in itself, since the fact that some policy would not benefit the least well-off would generally not be taken as a reason to reject it. Nonetheless, $I$ believe it is worth keeping in mind in relation to the following set of arguments.

${ }^{12}$ Geraldine Pratt and Brenda Yeoh, "Transnational (Counter) Topographies," Gender, Place, and Culture, vol. 10, n. 2. June 2003 , p. 162
}

of gender and race, among others) of transnational migration will be

Finally, open admission polici benefit those who are not materic positively harmful for those le affluent liberal states, including attract highly educated professior global economic competitivenes harmful to developing states, an states. According to a study co quarter to one-half of college-ed Mozambique, Kenya, Uganda, ar in countries such as Haiti and college graduates. ${ }^{14}$ On averag Caribbean region live abroad ir Africa, 18\% for Eastern Africa Africa. ${ }^{15}$

While the World Bank study r (for example, this phenomena $\mathrm{i}$ India, China, Brazil, and Indor policies of affluent liberal states states. Celia Dugger notes that, " can prove particularly cripplin! education." For example, other countries require at least one $n$ have, as a result of "fatal flows" to North America and Europt expectancies caused by pneumo quality of health care available recent years as tens of thousanc USA. ${ }^{17}$ By allowing for unre intensify these problems, since migrants who may enter their bt

\footnotetext{
${ }^{13}$ While one could argue that these citizenship requirements, many transnat citizens of the states to which they mig: from which they emigrate. Furthermore stemming from formal, but not substan

14 Celia Dugger, "Developing Lands $\mathrm{H}$

15 Devesh Kapur and John McHale, "\$ Your Best and Brightest: The Global Ho D.C.: Center for Global Development.

16 Celia Dugger, "Africa Needs a Mill November 26, 2004

${ }^{17}$ Celia Dugger, "U.S. Plan to Lure N
} 


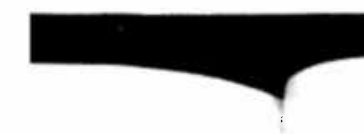

ze of open eral states. 'ise harmed And so, at -those for

? who they effects of Pratt and ostered by lobal poor. left intact, al poor are women in ny racially

en find ries and ce.' The contract the host me with pressive es even

liberating ty to cross ice, remain oh, that the nstitutions

[Citizenship here are two le is not that her, it is that egically it is r. Second, to immigration strictions on

d not benefit c it is worth

and Culture, of gender and race, among others) the more likely that the conditions and consequences of transnational migration will be harmful and exploitative. ${ }^{13}$

Finally, open admission policies in affluent liberal states would not merely fail to benefit those who are not materially able to migrate. In fact, such policies would be positively harmful for those left behind. Currently, the immigration policies of affluent liberal states, including the USA, Canada, Britain, and Australia, seek to attract highly educated professionals from developing states in order to improve their global economic competitiveness. Unsurprisingly, these policies can be extremely harmful to developing states, and in particular, to the least well-off in developing states. According to a study conducted by the World Bank, anywhere from onequarter to one-half of college-educated citizens in certain countries such as Ghana, Mozambique, Kenya, Uganda, and El Salvador live abroad in an OECD country, and in countries such as Haiti and Jamaica, this number rises to more than $80 \%$ of college graduates. ${ }^{14}$ On average, $41 \%$ of tertiary-educated individuals from the Caribbean region live abroad in an OECD country; this rate is $27 \%$ for Western Africa, $18 \%$ for Eastern Africa, 16\% for Central America, and 13\% for Central Africa. ${ }^{15}$

While the World Bank study notes that this trend is not consistent across the globe (for example, this phenomena is far less common in larger developing states like India, China, Brazil, and Indonesia), it nevertheless suggests that the admission policies of affluent liberal states can, in certain contexts, be harmful to developing states. Celia Dugger notes that, "the exodus of skilled workers from poor countries... can prove particularly crippling in much needed professions in health care and education." For example, other studies also reported by Dugger reveal that African countries require at least one million more healthcare workers than they currently have, as a result of "fatal flows" of nurses and doctors from poor African countries to North America and Europe, in order reverse the trend of plummeting life expectancies caused by pneumonia, AIDS, malaria, and tuberculosis. ${ }^{16}$ Similarly, the quality of health care available in the Philippines has deteriorated significantly in recent years as tens of thousands of nurses have moved abroad, particularly, to the USA. ${ }^{17}$ By allowing for unrestricted immigration, affluent liberal states would intensify these problems, since affluent liberal states currently limit the number of migrants who may enter their borders, even among so-called skilled workers. Those

\footnotetext{
${ }^{13}$ While one could argue that these sorts of problems could be addressed by the liberalization of citizenship requirements, many transnational labor migrants (temporary workers) do not wish to become citizens of the states to which they migrate, which often requires that they give up citizenship in the state from which they emigrate. Furthermore, the liberalization of citizenship requirements addresses problems stemming from formal, but not substantive, inequalities at best.

${ }^{14}$ Celia Dugger, "Developing Lands Hit Hardest by 'Brain Drain'," New York Times, October 25, 2005

15 Devesh Kapur and John McHale, "Should a Cosmopolitan Worry about the "Brain Drain"?" Give Us Your Best and Brightest: The Global Hunt for Talent and Its Impact on the Developing World, Washington D.C.: Center for Global Development, 2005

${ }^{16}$ Celia Dugger, "Africa Needs a Million More Health Care Workers, Report Says," New York Times, November 26, 2004

17 Celia Dugger, "U.S. Plan to Lure Nurses May Hurt Poor Nations," New York Times, May 24, 2006
} 
in developing states who are in a position to benefit from open borders in affluent liberal states, as noted above, are generally among the more privileged in developing states. And so, not only would liberalization of immigration restrictions in affluent liberal states generally be unhelpful to the least well-off in developing states, but, in addition, such admission policies in affluent liberal states would be positively harmful to the least well-off in developing states, since, as Dugger notes, "brain drain may also fuel a vicious downward cycle of underdevelopment" in developing states.

\section{Objections}

A central part of my argument in this paper has been that consequentialist cosmopolitan defenses of open borders have neglected certain empirical considerations that bear on the validity of their arguments. One relevant empirical concern that I have not considered so far is the effect of remittances by immigrants in affluent states to their family members in poorer parts of the world. Remittances appear to constitute a substantial form of income for poor countries, and some have argued that remittances have a significant effect in reducing poverty in many countries. Richard Adams and John Page note that official international remittances total $\$ 93$ billion per year; this amount represents the second most important source of external funding in developing countries and is about twice as large as the level of official aid-related inflows to developing countries. ${ }^{18}$ Perhaps, one might object, the consequentialist cosmopolitan defense of open borders is vindicated by considering the effect on remittances on poverty in poor countries.

Strictly speaking, however, this argument does not constitute an objection to my thesis. My argument has not been the affluent liberal states ought to close their borders (for the benefit of the global poor), or that there is no plausible rationale for the claim that liberal states ought to open their borders. Rather, I have argued that consequentialist cosmopolitan defenses of open borders are inadequate to the extent that they have neglected the social location of those affected by the immigration policies of affluent liberal states. My thesis is consistent with the claim that liberal states ought to open their borders on the grounds that remittances by immigrants from poor countries significantly reduce poverty in those countries. I have merely attempted to show that typical consequentialist cosmopolitan arguments in defense of open borders are, in themselves, unsuccessful.

I am, however, skeptical about the optimistic prognoses of World Bank economists such as Adams and Page regarding the effect of remittances on global poverty. While one could write an entire volume on this question itself, I would like to briefly raise a few concerns about the accuracy of these studies as well as the methodologies on which they are based. First, Adams and Page's study assumes a static level of poverty in poor countries; in arguing that remittances reduce the level of poverty in poor countries, they neglect the fact that one significant causal contributor to poverty in these countries is the exodus of citizens with skills and

\footnotetext{
18 Adams, Richard, and John Page, "Do International Migration and Remittances Reduce Poverty in Developing Countries?" World Development, v. 33, n. 10, pp. 1645-1669, 2005
}

education that are marketable in reduce poverty under conditions pervasiveness of poverty.

Additionally, reports of the ef generally not disaggregated acco country. This limitation of the benefiting from remittances. If tend to benefit most from open $\boldsymbol{c}$ who are already relatively adv among other things)-then th remittances (the families of th already relatively privileged. In of remittances supports the cons one must ask not only "Which $\mathbf{f}$ family members benefit from re

Finally, different reports on about the quantity and effect o reflect divergent methodologies international remittances, reg remittances are counted, amons considerations motivate the metl the quantity and effect of int immigration may exaggerate the that immigrants drain wealth fro may exaggerate the effect of rer claims that affluent countries Substantiation of these claims $v$ here; my goal, however, is not $t$ fact politically biased, but raths about whether or not affluent lit that remittances significantly red assess the methodological ass international remittances. Such a migration on global poverty-r must also investigate the distrib figures.

I have primarily argued in th the admission policies of libe support of this constraint sugge liberal states would, all things affected. Suppose for the sal

\footnotetext{
${ }^{19}$ See, for example, "Study challenges Malkin, in the New York Times, July actually receive from remittances. Also Caglar Ozden and Maurice Schiff substantially higher figures for the qui
} 
education that are marketable in affluent countries. In other words, remittances only reduce poverty under conditions that are themselves partially responsible for the pervasiveness of poverty.

Additionally, reports of the effect of remittances on poverty in poor countries are generally not disaggregated according to gender, race, and class-generally only by country. This limitation of these studies makes it impossible to know who is benefiting from remittances. If my previous argument is correct-that those who tend to benefit most from open admission policies in affluent liberal states are those who are already relatively advantaged (with respect to gender, race, and class, among other things)-then this suggests that those who benefit most from remittances (the families of those who migrate transnationally) are themselves already relatively privileged. In order to determine whether or not the consideration of remittances supports the consequentialist cosmopolitan defense of open borders, one must ask not only "Which families benefit from remittances?" but also "Which family members benefit from remittances?"

Finally, different reports on remittances draw markedly different conclusions about the quantity and effect of remittances in poor countries. ${ }^{19}$ Such differences reflect divergent methodologies and assumptions made by researchers investigating international remittances, regarding how "remittance" is defined, and how remittances are counted, among other things. It is certainly possible that political considerations motivate the methodological assumptions made by those investigating the quantity and effect of international remittances. For example, opponents of immigration may exaggerate the extent of remittances in order to rationalize the claim that immigrants drain wealth from the national economy, while neoliberal economists may exaggerate the effect of remittances on poverty in poor countries in response to claims that affluent countries participate in the "brain drain" of poor countries. Substantiation of these claims would require far more space than I have given them here; my goal, however, is not to prove that reports on international remittances are in fact politically biased, but rather, to demonstrate that in order to draw conclusions about whether or not affluent liberal states ought to open their borders on the grounds that remittances significantly reduce global poverty, one must carefully and reflectively assess the methodological assumptions of studies on the quantity and effect of international remittances. Such assessment must consider the net effect of transnational migration on global poverty - not simply the isolated effects of remittances-and it must also investigate the distribution of remittances instead of relying on aggregated figures.

1 have primarily argued in this paper in defense of a methodological constraint on the admission policies of liberal states, but the considerations I have raised in support of this constraint suggest that the elimination of restrictions on admission to liberal states would, all things considered, be more harmful than beneficial to those affected. Suppose for the sake of argument (and against my explicitly stated

${ }^{19}$ See, for example, "Study challenges assumptions about money being remitted to Mexico," by Elisabeth Malkin. in the New York Times, July 7, 2005, which questions how much money families of migrants actually receive from remittances. Also see International Migration, Remittances, and the Brain Drain, by Caglar Ozden and Maurice Schiff (World Bank and Palgrave Macmillan), 2006, which provides substantially higher figures for the quantity of remittances internationally than Adams and Page. 
intentions) that these considerations support extremely restrictive or even closed admission policies in affluent liberal states. Would it be paternalistic for affluent liberal states to deny admission to immigrants from poor countries on these sorts of grounds (i.e., for their own benefit)?

While I do not defend any substantive immigration policies in this paper (and so, in principle, this objection does not apply to my thesis and is based on a misunderstanding of my argument), I would nevertheless like to argue that affluent liberal states would not be acting paternalistically toward potential immigrants if they refused them admission for their own benefit. This objection misunderstands the nature of paternalism, which occurs only when $A$ restricts the freedom of $B$ for B's own benefit. I have argued in this paper that open borders in liberal states would harm both those who do not migrate and those who do. With regard to the former, were liberal states to refuse admission to potential immigrants for the benclit of those who do not migrate (to prevent "brain drain" for example), this would be a case, at best, of $\mathrm{A}$ restricting the freedom of $\mathrm{B}$ in order to benefit $\mathrm{C}$-not paternalism, but rather an application of Mill's Principle of Harm.

The case of the latter, where affluent liberal states refuse admission to potential immigrants for their own benefit (in order to prevent them from being exploited, as described, for example, by Pratt and Yeoh), is best understood, I argue, as "A not harming B," and is therefore not a case of paternalism. Even if this case is understood as "A restricting the freedom of B for B's own benefit," that is, as paternalism, I think the action of liberal states that refuse admission to potential immigrants for their own benefit bears morally salient differences from standard cases of paternalism that make such action morally justifiable. In standard cases of paternalism, A bears no moral or causal responsibility for the conditions under which, if $B$ acts in certain ways, B will be harmed. In the case in question-where liberal states refuse admission to potential immigrants to prevent them from being exploited, for example-liberal states themselves bear some, if not all, moral and causal responsibility for the conditions under which, if citizens of poor countries immigrate, they will be harmed. Suppose, for example, that I attempt to sell you a house which, I fail to disclose, contains deadly levels of carbon monoxide as a result of my own negligence. In the absence of this information, you are eager to buy the house from me. Just I am about to transfer the deed to you, my conscience prevents me going through with the sale. It seems clear that I am not behaving wrongly in this case; it is not even clear that 1 am behaving paternalistically--since I am responsible for the conditions under which you might be harmed. If my actions in this case are analogous to the actions of liberal states that deny admission to potential immigrants for their own benefit, then liberal states are not acting paternalistically by adopting restrictive admission policies, and they are certainly not acting wrongly.

\section{Conclusion}

None of this, however, is to suggest that affluent liberal states ought to close their borders; rather, these arguments demonstrate, contra the consequentialist cosmopolitans who call for open borders, that the elimination of immigration restrictions by affluent liberal states only appears as a remedy to global economic inequality under the adoption of an idealized social ontology, i individuals privileged with respect among others. Lack of attention to makes immigration policies that di disadvantaged groups appear moral

What immigration policies are answer that question. What 1 has sufficient condition on the justic believe that what immigration poli the next, not only because what salient varies with context, but a situated relative to other statc economically, and politically. $M_{1}$ adopt different policies governing states. For these reasons, one ce ought to adopt prior to investigati that national context, as determin among others yet to be specified.

Nevertheless, while I am agn varying national contexts, provisi. of open admission policies by libs at the very least, the formal right aliens and temporary workers, $\varepsilon$ proportion to the number of imr admission policies by affluent lib Organization, among other institı institutions are substantially resp. inequality which may undermint regulating immigration. 
losed fuent rts of

Id so,

on a

fluent

nts if

tands

$B$ for

vould

irmer,

fit of

be a

-not

ential

ed, as

A not

ise is

is, as

ential

ndard

ses of

under

where

being

al and

intries

you a

result

uy the

events

in this

nsible

ise are

grants

opting

of an idealized social ontology, in which the world is exclusively constituted by individuals privileged with respect to the social institutions of gender, race, and class, among others. Lack of attention to the way in which individuals are socially situated makes immigration policies that disproportionately burden members of institutionally disadvantaged groups appear morally justified.

What immigration policies are just? Based on what I have argued so far, I cannot answer that question. What I have defended in this paper is a necessary, but not sufficient condition on the justice of a state's admission policies. In addition, I believe that what immigration policies are just will vary from one national context to the next, not only because what social aspects of a person's identity are morally salient varies with context, but also because each state is uniquely institutionally situated relative to other states within the international order, historically, economically, and politically. Moreover, justice may require a receiving state to adopt different policies governing the admission of migrants from different sending states. For these reasons, one cannot determine what immigration policy a state ought to adopt prior to investigation of the considerations that are morally salient in that national context, as determined by the methodological constraint I defend here, among others yet to be specified.

Nevertheless, while I am agnostic about which immigration policies are just in varying national contexts, provisionally, I would like to suggest that for the adoption of open admission policies by liberal states to be just, liberal states must first extend, at the very least, the formal rights and benefits of citizenship to permanent resident aliens and temporary workers, and second, fairly compensate sending nations in proportion to the number of immigrants admitted. Finally, the construction of just admission policies by aftluent liberal states may require reforms to the World Trade Organization, among other institutions of the global economic order, insofar as such institutions are substantially responsible for the conditions of poverty and economic inequality which may undermine the options affluent liberal states have for justly regulating immigration.

e their olitans ffluent option 